\title{
IATROGENIC LESIONS IN BABIES FOLLOWING UMBILICAL VEIN CATHETERIZATION
}

\author{
BY \\ JEAN M. SCOTT
From The Royal Maternity Hospital, Glasgow
}

(RECEIVED FOR PUBLICATION OCTOBER 15, 1964)

During a study of babies with respiratory distress syndrome (RDS) and of the effects of intravenous bicarbonate and laevulose on glycogen reserves of the newborn (Scott, 1965), it was found that 2 babies developed complications arising out of treatment. One had an umbilical vein thrombosis with large pulmonary embolus. The other developed umbilical sepsis with a thrombophlebitis and pyaemia. It was, therefore, decided to carry out a more detailed examination of the vein and its branches in all future cases coming to necropsy in order to investigate the significance of these findings.

\section{Material and Methods}

During the period under review 200 babies with RDS received bicarbonate and laevulose via the umbilical route (Hutchison, Kerr, Douglas, Inall, and Crosbie, 1964) and 92 of these came to necropsy: 35 belonged to the original series in which glycogen studies were made. Routine blocks were taken through the umbilicus after it had been carefully examined for evidence of sepsis. The umbilical vein and its branches within the liver were then opened longitudinally and the findings were noted. Serial transverse sections of the vessel, including adjacent liver substance, were taken in all cases where lesions existed, and in the latter part of the survey random blocks were selected, even in the absence of any gross pathology. Careful attention was also paid to pulmonary vessels and several blocks of lung were examined. In addition, routine blocks from other organs were also taken.

During the survey one Rhesus negative baby died following replacement transfusion, and this case was similarly examined, and older post mortem-material from 14 babies dying after replacement transfusion was reviewed.

\section{Results}

In this department it has always been the custom to take a routine block of umbilicus at necropsy for microscopical examination. Thus any changes resulting from catheterization were immediately noticeable. These consisted of slight oedema of the wall of the vein and occasionally a diffuse mild polymorph infiltrate involving all coats. Frequently adventitial haemorrhages were also found. Babies who had had replacement transfusions showed similar features, but here the changes were not as marked as in those titrated with bicarbonate and laevulose. In the latter group an aseptic necrosis of the endothelium of the wall of the vein with subsequent fibrin deposition was also found. Remnants of nuclear material, staining black in $\mathrm{H}$. and $\mathrm{E}$. sections and positive for Feulgen, were occasionally seen in this fibrin or plastered against the wall of the vein. In the majority, this change remained localized to the umbilicus, but in 18 of the 92 babies examined, or approximately $20 \%$, more extensive lesions were observed. Details of these are shown in the Table, where it can be seen that they fell into 4 main groups.

Group I. Cases 1 to 3 belonged to this group and in these babies changes similar to those noted in the umbilicus were seen in the umbilical vein and in its main branches within the liver substance (Fig. 1). There was no evidence of any thrombus formation, but small haemorrhages were frequent, around the vein, usually where one might have expected the tip of the catheter to lie.

Group II. Cases 4 to 9 were in this group and all had a spreading thrombosis of the umbilical vein and its main branches within the liver substance (Fig. 2). This was obvious on naked eye examination and most frequently the right branch, linking up with the portal vein, was the one involved. Haemorrhages in the vein wall and in the surrounding adventitial tissue were marked, and when serial blocks of the area were examined, it was found that in 4 instances (Cases 4, 5, 6, and 7) the thrombosis had spread further into portal tracts. A mid-zonal necrosis was present in Case 6 which lived for 146 hours (Fig. 3). This was obvious to the naked eye and involved both 
TABLE

CHANGES IN UMBILICAL VEIN AND DEGREE OF SPREAD

\begin{tabular}{|c|c|c|c|c|c|c|}
\hline Case No. & Weight (g.) & Age (hr.) & $\begin{array}{l}\text { Age (hr.) when } \\
\text { catheterized }\end{array}$ & $\begin{array}{l}\text { Catheter in } \\
\text { (hr.) }\end{array}$ & $\begin{array}{l}\text { Grade of } \\
\text { Spread }\end{array}$ & Necropsy \\
\hline $\begin{array}{l}1 \\
2 \\
3 \\
4 \\
5 \\
6\end{array}$ & $\begin{array}{r}920 \\
760 \\
1,160 \\
1,940 \\
2,060 \\
1,220\end{array}$ & $\begin{array}{r}17 \\
72 \\
168 \\
71 \\
52 \\
146\end{array}$ & $\begin{array}{l}3 \\
2 \\
3 \\
6 \\
5 \\
4\end{array}$ & $\begin{array}{l}14 \\
46 \\
48 \\
48 \\
47 \\
64\end{array}$ & $\begin{array}{l}\text { I } \\
\text { I } \\
\text { I } \\
\text { II } \\
\text { II } \\
\text { II }\end{array}$ & $\begin{array}{l}\text { Atelectasis, patchy HMD } \\
\text { Extreme prematurity, atelectasis } \\
\text { Coliform meningitis, HMD } \\
\text { Pneumonia, HMD, kernikterus } \\
\text { IVH, HMD } \\
\text { HMD umbilical vein thrombosis, } \\
\text { hepatic necrosis, early } \\
\text { pneumonia }\end{array}$ \\
\hline $\begin{array}{l}7 \\
8 \\
9\end{array}$ & $\begin{array}{l}1,120 \\
1,500 \\
1,860\end{array}$ & $\begin{array}{r}100 \\
21 \\
31\end{array}$ & $\begin{array}{r}4 \\
2 \\
20\end{array}$ & $\begin{array}{l}96 \\
19 \\
11\end{array}$ & $\begin{array}{l}\text { II } \\
\text { II } \\
\text { II }\end{array}$ & $\begin{array}{l}\text { IVH, HMD, pneumonia } \\
\text { IVHs, TT, HMD } \\
\text { HMD?? foetal blood loss; } \\
\text { placenta praevia }\end{array}$ \\
\hline $\begin{array}{l}10 \\
11\end{array}$ & $\begin{array}{l}1,060 \\
1,660\end{array}$ & $\begin{array}{l}21 \\
58\end{array}$ & $\begin{array}{r}11 \\
3\end{array}$ & $\begin{array}{l}10 \\
55\end{array}$ & $\begin{array}{l}\text { III } \\
\text { III }\end{array}$ & $\begin{array}{l}\text { ICH, TT } \\
\text { HMD, pulmonary embolus }\end{array}$ \\
\hline $\begin{array}{l}12 \\
13\end{array}$ & $\begin{array}{l}1,100 \\
2,180\end{array}$ & $\begin{array}{r}34 \\
121\end{array}$ & $\begin{array}{r}4 \\
28\end{array}$ & $\begin{array}{l}30 \\
93\end{array}$ & III & $\begin{array}{l}\text { IVH, HMD } \\
\text { HMD, umbilical vein thrombosis, } \\
\text { hepatic necrosis (mid-zonal), } \\
\text { diabetic mother }\end{array}$ \\
\hline $\begin{array}{l}14 \\
15 \\
16\end{array}$ & $\begin{array}{r}1,420 \\
2,460 \\
920\end{array}$ & $\begin{array}{l}12 \\
33 \\
96\end{array}$ & $\begin{array}{r}4 \\
25 \\
6\end{array}$ & $\begin{array}{r}8 \\
8 \\
47\end{array}$ & $\begin{array}{l}\text { III } \\
\text { III } \\
\text { IV }\end{array}$ & $\begin{array}{l}\text { IVHs, HMD } \\
\text { HMD } \\
\text { Pyaemia, pneumonia, umbilical } \\
\text { sepsis }\end{array}$ \\
\hline 17 & 1,200 & 54 & 3 & 21 & IV & $\begin{array}{l}\text { Pyaemia, umbilical vein thrombo- } \\
\text { phlebitis, IVH }\end{array}$ \\
\hline 18 & 2,120 & 94 & 35 & 59 & IV & $\begin{array}{l}\text { Pyaemia, umbilical vein thrombo- } \\
\text { phlebitis, HMD, early } \\
\text { pneumonia }\end{array}$ \\
\hline
\end{tabular}

HMD = hyaline membrane disease; IVH = intraventricular haemorrhage; ICH $=$ intracranial haemorrhage; and TT $=$ tentorial tear.

lobes. Case 7 was interesting: the baby was born at home and its cord had been dusted with powder; doubly refractile material was present both in the thrombus within the liver and in the block from umbilicus.
Group III. There were 6 cases (Cases 10 to 15) with pulmonary emboli. Apart from Case 11, the emboli were small and frequently multiple. They varied in age, some showing early organization. No. related vascular upset, such as congestion or

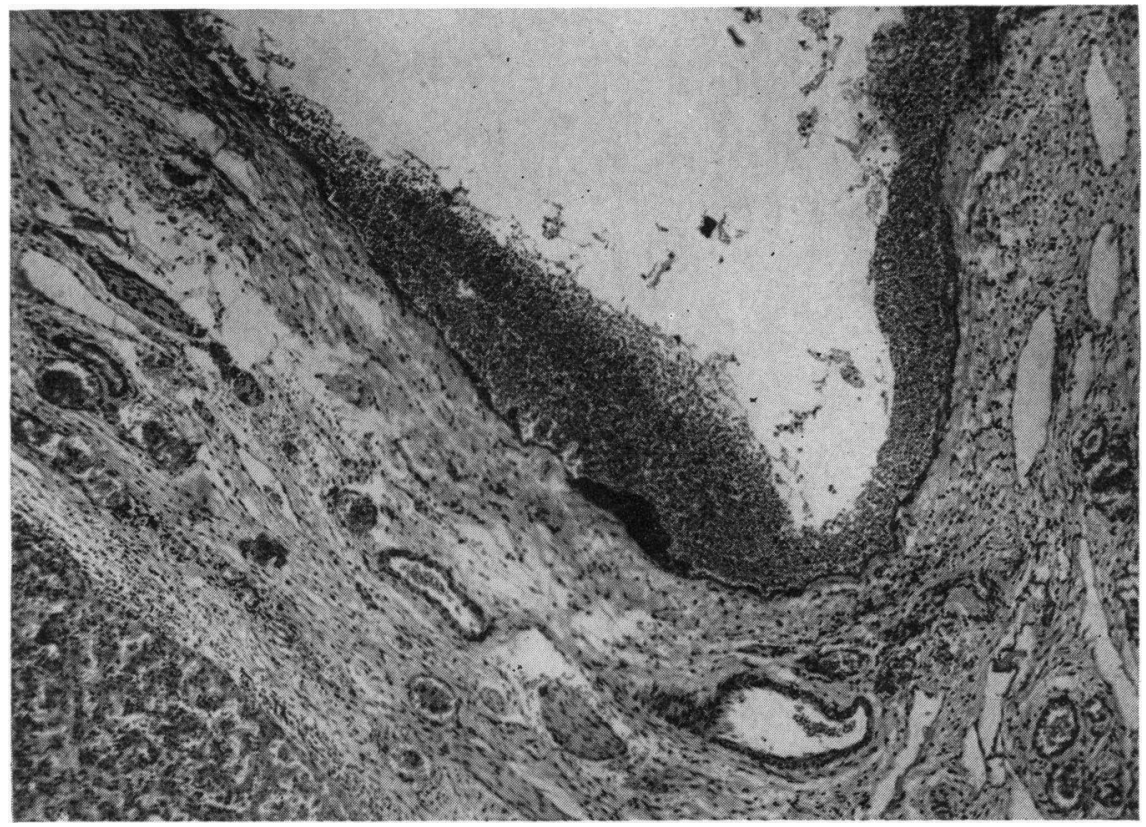

FIG. 1.-Major branch of umbilical vein within liver showing endothelial necrosis and blue-black mass, positive for Feulgen, plastered against wall of vein. (H. and E. $\times 66$. 


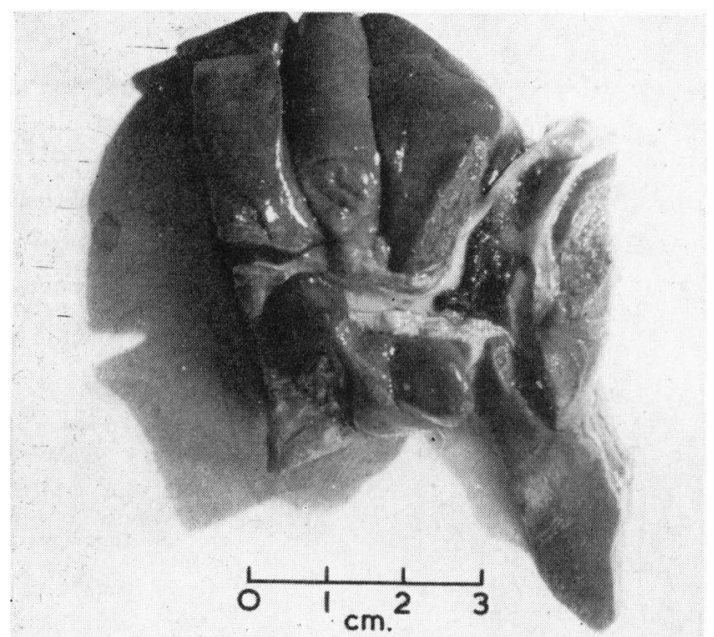

FIG. 2.-Umbilical vein opened longitudinally to show spreading thrombus.

haemorrhage, could be seen, and collapse was difficult to assess since resorption atelectasis due to the primary condition was so widespread. Thus diagnosis was not made until the lungs were examined microscopically.

In Cases 14 and 15, where the catheter had been in situ for only 8 hours, no thrombus was found in the umbilical vein. Case 15 was a late catheterization at 20 hours: this baby had been born at home and the cord dusted with powder; in one of the emboli doubly refractile material resembling hairs and a starch granule were found. All the other babies had umbilical vein thrombosis and Case 13 developed liver necrosis. As already stated a large pulmonary embolus was present in Case 11: this was recognized at necropsy, and clot filled a main branch of the left pulmonary artery and spread into the lung substance. No gross circulatory upset was evident.

Group IV. Infection developed in 3 (Cases 16, 17, and 18 ), where there was an umbilical vein phlebitis and septic emboli were seen within the liver and lung. In Case 16 an embolus had settled in the atrial appendage of the right atrium. At necropsy the whole appendage was distended with rather friable clot, and microscopically an inflammatory reaction could be seen spreading into the wall of the appendage.

Apart from one case of umbilical sepsis, thrombophlebitis, and septicaemia, none of the 15 Rhesus babies showed any of the above lesions. The case in which sepsis occurred was a late catheterization with replacement transfusion 24 hours after delivery outside.

\section{Discussion}

Routine examination of the umbilical vein in untreated babies dying with RDS or similar condition associated with marked venous congestion frequently reveals thrombus within the vein, but this is always

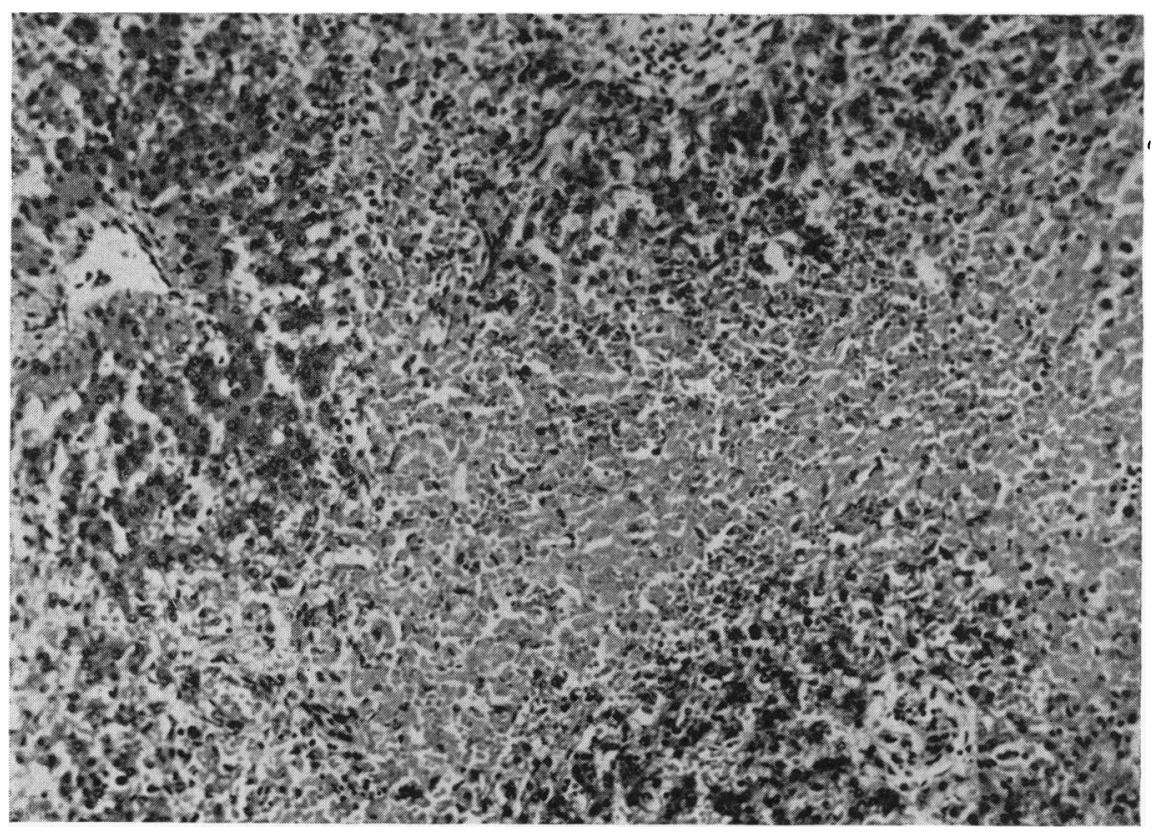

FIG. 3.-Liver showing mid-zonal necrosis. (H. and E. $\times 145$.) 
agonal in type and never adherent like the clot occurring in catheterized babies; nor is there evidence of haemorrhage or associated trauma as in the latter group.

Since all babies, including the Rhesus group, show changes at the level of the umbilicus and only a few develop more extensive lesions, it is doubtful if these local effects have any real significance. Any attempt to relate endothelial necrosis and its sequelae to bicarbonate and laevulose administration, as distinct from blood, would be unwise since the catheter was in situ considerably longer in titrated cases, and the question of continued trauma then arises.

Only $20 \%$ of the babies coming to necropsy showed lesions extending beyond the umbilicus. This figure should possibly be higher since only gross lesions were recorded in the first part of the survey, and hence no Group I cases were reported at that time. This in no way alters the picture however, for reference to the Table will show that it is very doubtful whether these Group I lesions have any real clinical significance. Two of the babies were extremely premature, under $1,000 \mathrm{~g}$., and in the third which died of meningitis, there was no evidence to suggest that the umbilical route had been the portal entry for infection.

Of the remaining 15 cases in groups II, III, and IV, it can be seen that many of the babies died from other causes and it is doubtful whether the iatrogenic lesions influenced the ultimate course of events. There were, however, 6 cases where they apparently played a more significant part (Cases $6,11,13,16,17$, and 18). Umbilical vein phlebitis and pyaemia accounted for three, umbilical vein thrombosis and liver necrosis for 2 , and a large pulmonary embolus for the last. In all but one the catheter had been in situ for $\mathbf{4 7}$ hours or more, and the exception had an intraventricular haemorrhage that probably hastened death. When one considers, however, that during this period of survey 200 babies were treated and the mortality rate fell from 66 to $46 \%$ (Hutchison et al., 1964) this number is relatively small. Though it did seem in these 6 cases that lengthy catheterization might carry an added risk it does not necessarily follow from this that the type or extent of lesion observed can be related to duration of catheterization. Too many other factors such as positioning of tip of catheter, possibility of local trauma, propor- tions of bicarbonate and laevulose used, and even tendency to thrombosis, are all involved. None the less, the pathological picture is clear; the earliest lesion consists of an aseptic endothelial necrosis, resulting in local and eventually spreading thrombosis involving the liver in certain cases. Embolism may well occur when fluids are being administered and, as these were given hourly, this would explain why emboli of various ages were seen in the lungs. More important still is the fact that these minor embolic episodes were 'silent' and the question arises whether any of the survivors suffered similarly. If so, it will be interesting to see whether any of these survivors subsequently develop signs of pulmonary abnormality such as has been reported in adults following thromboembolism by Wood (1956) and Emmanuel (1961).

\section{Summary}

Of 200 babies treated with bicarbonate and laevulose via an umbilical vein catheter for respiratory distress syndrome, 92 came to necropsy. Complications arising from this form of therapy occurred in $20 \%$ of those that died, but in the majority of these other factors were responsible for death. Only in 6 instances was it felt that iatrogenic lesions could be regarded as immediate causes: 3 were cases of umbilical vein phlebitis and pyaemia; 2 had thrombosis and liver necrosis, and 1 had a large pulmonary embolus. The findings were compared with those seen in 15 Rhesus babies dying after replacement transfusion: amongst these there was only one case of umbilical vein phlebitis, and this was a late catheterization at 24 hours.

I would like to acknowledge the help and encouragement I have received from Dr. A. D. T. Govan. I am also grateful to Professor Hutchison for permission to study his case records and to Mr. Andrew Fraser and Mr. T. Pearston for photographic illustrations.

\section{REFERENCES}

Emmanuel, R. W. (1961). Pulmonary hypertension and mitral valvular disease in relation to anticoagulants. In Symposium on Anti-coagulant Therapy, ed. Sir G. W. Pickering, p. 271. Harvey and Blythe, London.

Hutchison, J. H., Kerr, M. M., Douglas, T. A., Inall, J. A., and Crosbie, J. C. (1964). A therapeutic approach in 100 cases of the respiratory distress syndrome of the newborn infant. Pediatrics, 33, 956.

Scott, J. M. (1965). Histological observations on glycogen reserves of the foetus and newborn infant. Arch. Dis. Childh., 40, 317.

Wood, P. H. (1956). Diseases of the Heart and Circulation, 2nd ed. Eyre and Spottiswood, London. 